distal extremities of the fingers, and there is always a history of chronic pulmonary disorder. The abnormal perspirations, palpitations, flushings, exophthalmos, and sleeplessness met with in some cases of acromegaly, especially if associated with goitrous enlargement of the thyroid gland, may arouse some suspicion of Graves's disease, but careful observation will soon set any initial doubts at rest. Similarly it is necessary to remember that diabetes may be a manifestation of acromegaly, because the existence of the former in an acute form may so fill in the picture as to obscure the acromegalic condition to which it is secondary.

Pathology. - On examination after death the skull is frequently found enlarged as a whole, the external surface is rough, especially at the seats of muscular and ligamentous attachments, and the occipital protuberance is sometimes unduly prominent. The facial bones, and especially the body and rami of the lower jaw, are hypertrophied. The protruding position of the lower jaw prevents the teeth coming in apposition with those of the upper jaw, which it overlaps. In a certain proportion of cases the vertebral column shows a kyphotic curve in the lower cervical and upper dorsal region. The ribs and sternum are compact and thickened; the rib cartilages are often considerably ossified. The clavicles may be enlarged at their ends. The metacarpi and metatarsi are thick and flat but not much altered, neither are very pronounced changes found in the phalanges, though their whole shape is abnormally massive, The epidermis is increased in thickness, the sweat glands are hypertrophied, and the sebaceous glands are prominent. The muscles are usually poor, and some of them are frequently atrophied. The arteries are dilated and thickened, and the heart is usually enlarged, especially in its left ventricle. In some instances, but not always, the thymus gland is preserved at its full size. The thyroid is seldom normal ; it may be found atrophied but more frequently it is enlarged. Degenerative changes of varying nature are found throughout the nervous system. The hypophysis cerebri or pituitary body is nearly ailways enlarged, especially in its anterior part. In some cases simple hypertrophy is described, in others the tissue change possesses all the characters of a simple adenoma, and in a few it has proved to be truly sarcomatous. The enlarged gland may increase downwards and find its way into the sphenoidal sinuses; if it extends internally it may penetrate one of the cavernous sinuses, and when the hypertrophy is considerable it may compress the frontal lobes anteriorly and the pedunculi cerebri posteriorly. The optic chiasma is usually more or less flattened, and the optic tracts are often atrophied. The mucous membrane of the mouth and soft palate is thickened, sometimes to a very considerable degree.

Numerous theories have been advanced to explain the disease. It has been variously ascribed to nervous abnormality ; to persistence of the thymus gland; to changes in the pituitary body; and to an anomalous retrogression to a lower ancestral type.

The balance of eridence is in favour of the theory that the pituitary body is chiefly responsible, but there is one great difficulty to contend with in unreservedly accepting this as the whole explanation-viz., that tumours of the hypophysis cerebri have been found post mortem in patients who had no symptoms of acromegaly. It has been suggested that the pituitary body, though enlarged, continues active, but that its duct becomes obliterated, so that its secretion becomes an "internal secretion" which is absorbed by the lymphatics.

Treatment.-Too much must not be expected from treatment. Reliance at present is placed almost exclusively on pituitary and thyroid extracts. Thyroid extract must always be given guardedly because its too bold administration may accelerate the decline of strength or cause permanent glycosuria. Pituitary-body extract is preferable and some good appears to come from its use in a fair proportion of cases. Iodide of potassium and one or other of the salts of mercury have been recommended, but except in cases where there is a specific taint their value seems doubtful. The general health of the patient must be carefully watched and every precaution taken to preserve his strength. Should glycosuria declare itself active dietetic measures at the first onset may succeed in quickly getting rid of the sugar. Constipation, which is always a source of trouble, must be dealt with by simple aperients and by an ample supply of fruit and vegetables. Headache may often be relieved by the exhibition of antipyrin, antifebrin, phenacetin, or exalgine. The sweatings are fairly well controlled by oxide of zinc, atropin, or picrotoxin. Frequent change of scene, massage, electricity, and hydrotherapy should all be resorted to under proper conditions; they contribute to the comfort of the patient and preserve within him the hopeful spirit.

\section{FEATURES OF SOME CHRONIC AFFEC- TIONS OF THE LUNGS IN CHILDREN.}

By THEODORE FISHER, M.D. LOND., F.R.C.P. LOND., ASSISTANT PHYSICIAN TO THE EAST LONDON HOSPITAL FOR CHILDREN, SHADWELL, E.

THE widespread examination of children in elementary schools, which has now become compulsory, will no doubt lead to the discovery in not a few instances of unexpected conditions of the lung and also of the heart. In the event of such discovery care will need to be exercised lest too serious an opinion should be given. Possibly some of the cases to which reference will be made here will illustrate a few of the difficulties which may arise in stating definitely the precise nature of disease of the lung.

The infrequency of chronic tuberculosis of the lungs in children is well known, yet possibly comparatively uncommon though the disease is realised to be, it may sometimes be diagnosed even by competent observers where it does not exist. Dilatation of the bronchial tubes may be limited, or almost entirely limited, to the upper lobe of one lung. When dilated bronchial tubes occupy this position it is scarcely necessary to remark that the physical signs which will be present may closely resemble the signs of cavitation or of fibrosis of the lung due to tuberculosis. The first case illustrating dilatation of the bronchial tubes in the upper lobe in a child came under my notice several years ago when I was registrar to the Royal Waterloo Hospital In a boy, aged two and a half years, dulness and bronchial breathing were present over the right upper lobe. After the boy had been in the hospital for two or three weeks it was thought that the condition might be a localised empyema. A needle was inserted and pus was drawn off. Later a small incision was made but only about two ounces of pus were evacuated. Eventually the child died. The wound in the chest wall was found to lead into a group of extremely dilated bronchial tubes and the remainder of the lobe was almost entirely composed of bronchial tubes dilated to less degree. The lower lobe was solid owing to the presence of septic pneumonia, but in this labe only here and there slight dilatation of the bronchial tubes was present. A few similar cases have been met with in the post-mortem room, and other cases which I believe to have been of the same nature have been seen clinically. Of those seen in the post-mortem room more than once it has happened that the child, in whom the dilatation of the bronchial tubes in the upper lobe has been present, had died from some disease unconnected with the condition of the lung. Thus in a boy, aged nine years, who died from diphtheria, the whole of the right upper lobe had been transformed into a collection of dilated bronchial tubes. The child also from whom the lung was removed which is represented in Fig. 1 died from diphtheria. The specimen is not as good a one as I should have liked. It does not show a section through the lung allowing comparison between the upper and lower lobes. Above are two superimposed sections of the upper lobe of the right lung and below is a section through the middle lobe. There were a few dilated bronchial tubes in the middle lobe but the lower lobe was unaffected. While not very satisfactory as a specimen it illustrates moderately well widespread dilatation of the bronchial tubes in an upper lobe of the Iung. The specimen was removed from a boy, aged five years, who died, as has been mentioned, from diphtheria. No satisfactory history could be obtained from the parents. He was said, however, to have been delicate and to have had "a cough since birth." As has already been suggested, one feature of importance of such cases as these seems to be that they may be mistaken for chronic tuberculosis of the lungs. Closely connected with the possibility of such a mistake is the question of prognosis. Before, however, briefly referring to prognosis, a few comments may be made upon the etiology of dilatation of the bronchial tubes.

When limited to a portion of a lobe or to one lobe, or perhaps when affecting both lower lobes, dilatation of the 


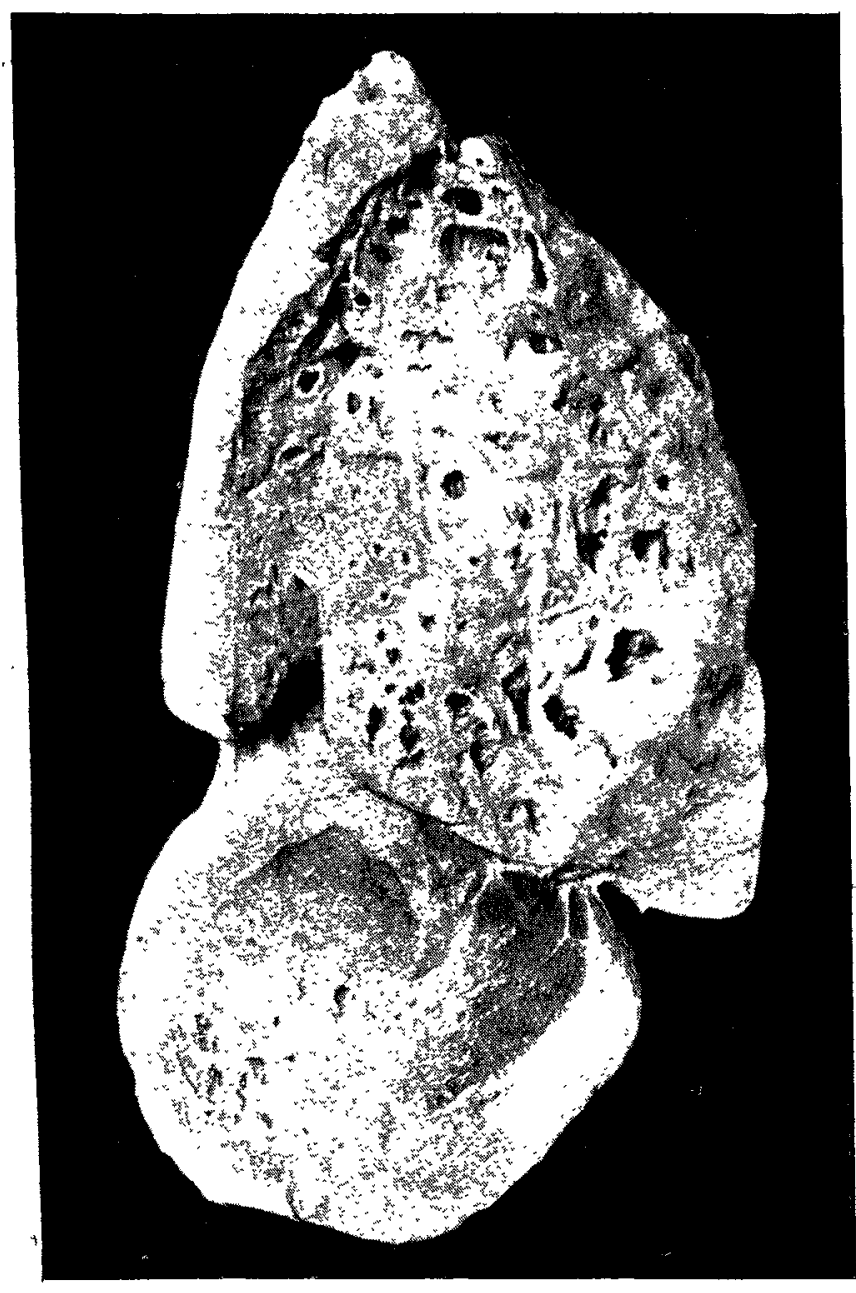

FIG. 1.-A section of the upper and mirllle lobes of the right throughout the upper lowe.

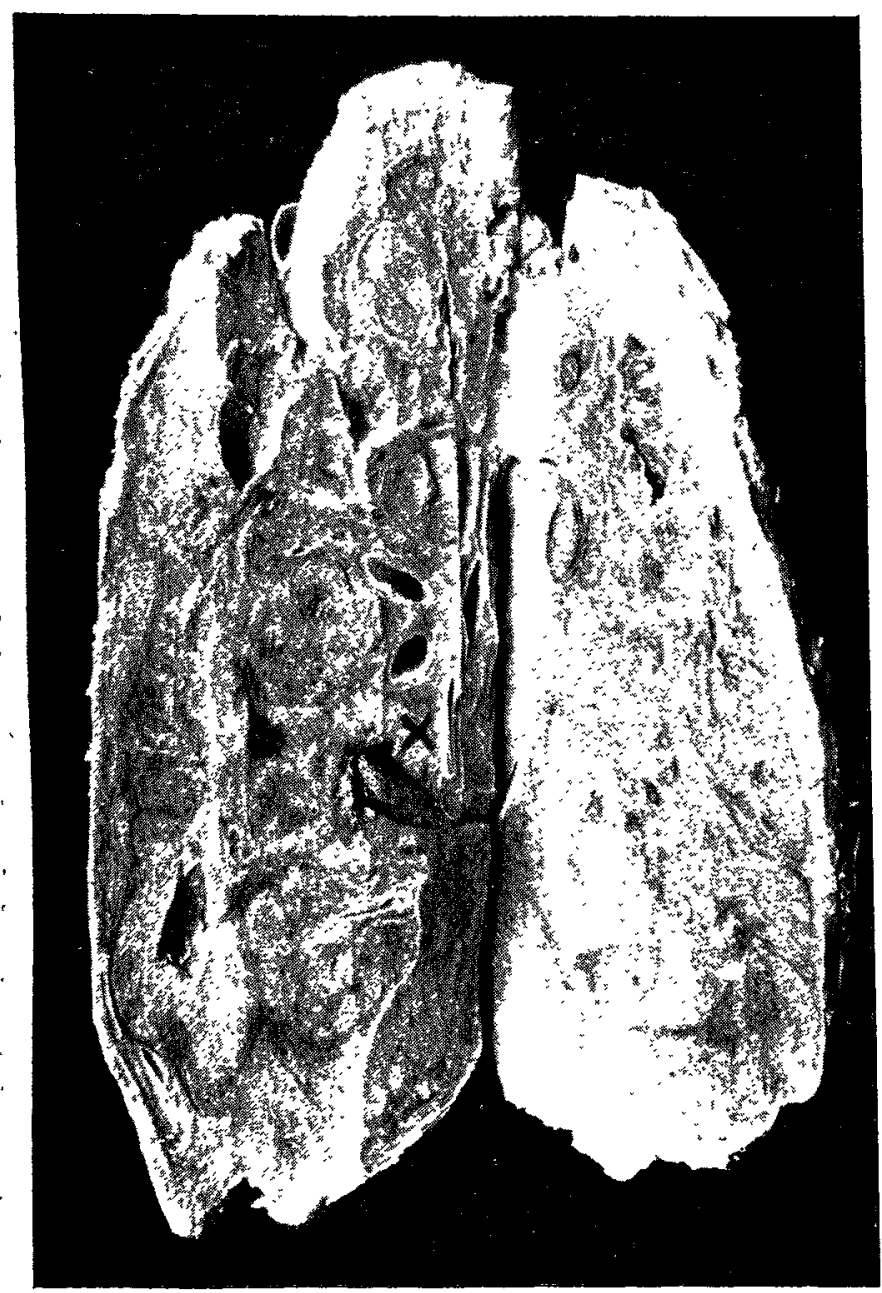

Fis. 3.-The left lnng of a girl cut open. It is fibroid throughout and shows below the mark $x$ the end of a portion of a metal tracheotomy tube.

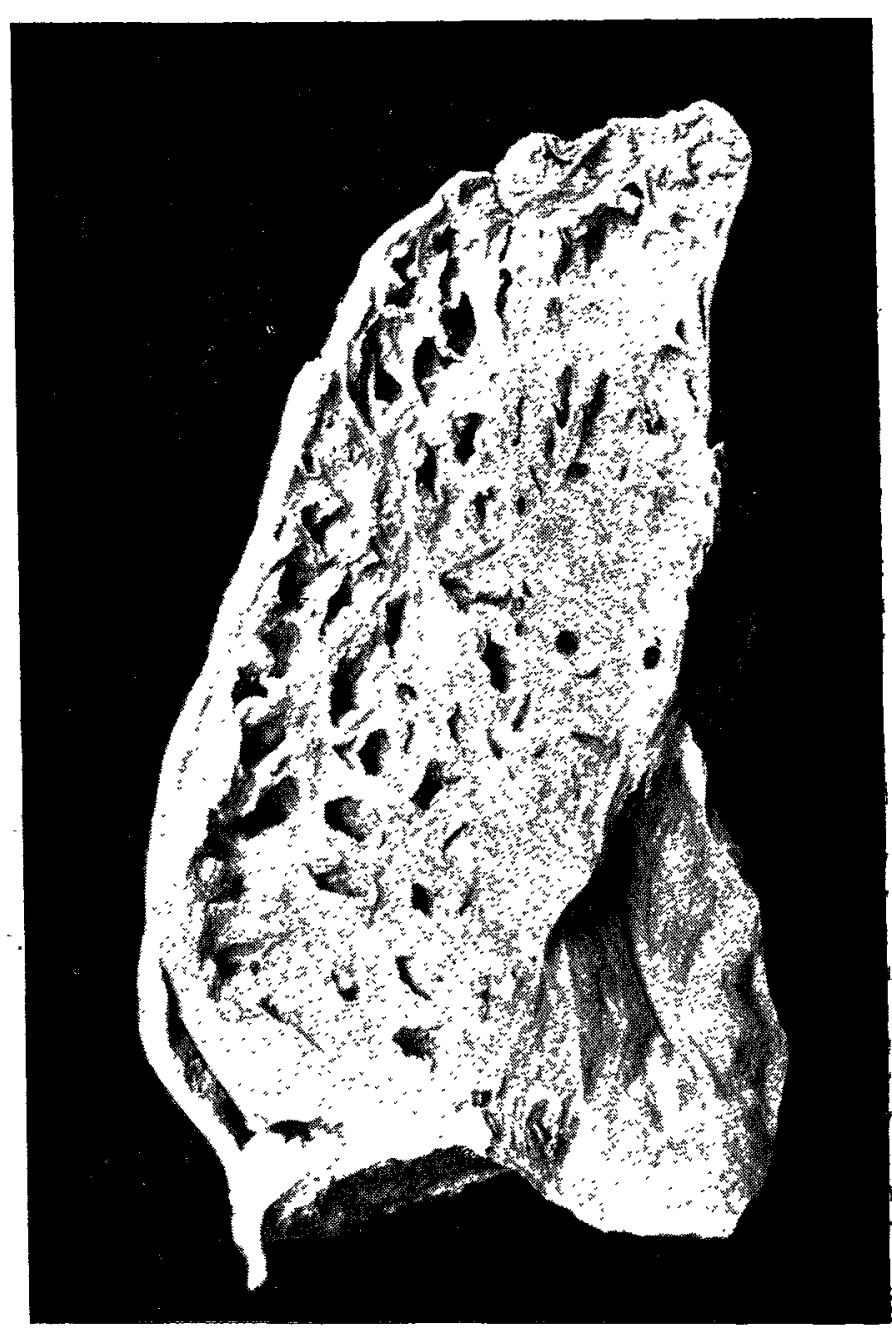

FIG. 2.-A section of the left lung of a child, showing general dilatation of the bronchial tubes.

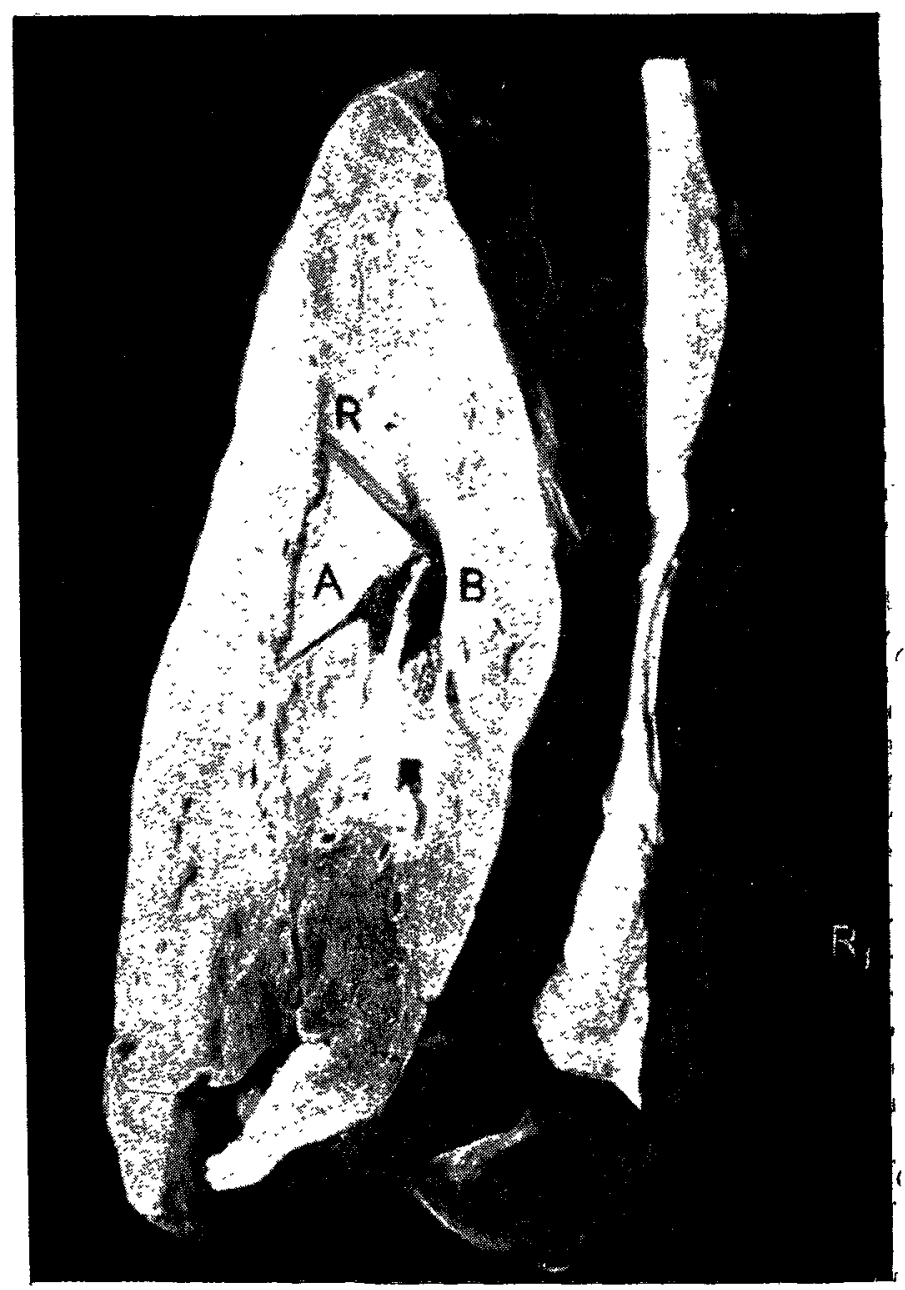

FIG. 4. - A section through the lower lobe of the left lung of a child with the cesophagus laid open attached. A glass rod $\mathbf{R}_{\mathbf{H}}$ passes through the cavity of an abseess which had originated in a bronchial gland $B$ and had burst into the osophagus. $A$ is a branch of the pulmonary artery which was opened by the abscess and led to fatal hemorrhage. 
bronchial tubes is probably generally secondary to bronchopneumonia. Occasionally, however, the dilatation may affect the whole of one lung. Fig. 2 represents a section of the lung of a child in which widespread dilatation is present. The photograph was taken from a specimen in the Bristol Royal Infirmary museum of which, unfortunately, there is no history. It seems probable, however, that in such a case the dilatation of the bronchial tubes has followed the presence of a foreign body in the bronchus. A case of this nature has come under my notice, but it did not occur in a patient of my own nor did I make the post-mortem examination. was, however, examined by me during life and I saw the affected lung after death. The case was as follows. A child had suffered from a chronic affection of the lungs for two or three years after a small steel object had entered one of the bronchi. When the child was examined there were signs over the whole of the right lung suggesting extensive chronic disease. The child died and after death the whole lung presented dilatation of the bronchial tubes. The foreign body was no longer present, but doubtless this had rusted away or had been expectorated after it had lodged in the bronchus sufficiently long to set up mischief in the lung.

Foreign bodies in the bronchus, as is well known, very commonly occasion a septic pneumonia which proves fatal. In some cases, however, it appears that inflammation has been set up which is not sufficiently acute to cause death, but in subsiding, like some other forms of broncho-pneumonia, it leads to dilatation of the bronchial tubes. It is possible that not only in cases of dilatation of the bronchial tubes affecting the whole of one lung, but when the dilatation is limited to one lobe it may have originated in the former presence of a foreign body. The following case suggests such a connexion. Over the lower lobe of the lung of a little girl who suffered from chronic congh, dulness, bronchial breathing, and intense bronchophony were present. The history given was that eight months previously the child had been seized with "a violent fit of coughing which could not be stopped and which left her very exhausted." A medical man was called in four days later who found the child feverish. Inflammation of the lungs, for which she was kept in bed for two months, followed. Such a history was strongly suggestive that the origin of the affection of the lung had been the presence of a foreign body in the bronchus; yet at first the mother denied the possibility of such an occurrence. A week later, however, she stated that she remembered that on the day on which the violent fit of coughing occurred the child had screamed, saying that an "acid drop" had "gone down the wrong way." A sweet is not a foreign body of so serious a nature as a pea or a small metal object, yet probahly it would remain undissolved in the bronchus sufficiently long to cause retention of secretion, which becoming infected with micro-organisms would set up the confluent broncho-pneumonia that may be seen in fatal cases of obstruction of a bronchus or of a division of a bronchus.

The case from which Fig. 3 was taken illustrates chronic disease of the lung as a sequel of the presence of a foreign body in the bronchus, but the main morbid condition is fibrosis, not dilatation of the bronchial tubes. It represents the left lung of a girl, aged 17 years, which has been laid open. Towards the lower part of the specimen is a triangular dark object. This is the end of a valve of a metal tracheotomytube. The girl during 13 years had worn a tube in the trachea following tracheotomy for a scalded throat. Four years before death a tracheotomy-tube was said to have been broken but it was asserted to have been of vulcanite. It is probable, however, that during the space of 13 years she broke more than one tube, and allowing the statement to be true that the only tubes she remembered had been of vulcanite this portion of a metal tube must have been lodged in the lung for several years before death.

While dilatation of the bronchial tubes if extensive is often a serious condition, the prognosis can scarcely be considered to be always grave. Not a few cases of dilatation of the bronchial tubes do not show the puffy, bad-complexioned, pale face, the clubbed fingers, and abundant expectoration considered to be in great measure characteristic of the affection. When these features are present some degree of poisoning is probably taking place from the contents of the dilated tubes and prolonged lillhealth ending in death is no doubt to be expected. But the whole of one lobe or perhaps the whole of two lobes may be destroyed without such an untoward event happening. In some cases it appears that nothing worse occurs than that the affected lobe ceases to grow, the healthy lobe perhaps expanding, without necessarily becoming emphysematous, and filling up the greater part of the space which the diseased lung should occupy within the chest I once made a necropsy on a woman aged about 60 years who had died during an attack of paroxysmal tachycardia. The left lower lobe was scarcely larger than a closed fist and was composed almost entirely of dilated bronchial tubes. I have seen also, after death in an adult, both lower lobes of the lungs of this small size and possessing only dilated bronchial tubes, unsurrounded by aircontaining lung tissue where there was nothing to suggest that in recent years there had been ill-health arising from any morbid condition in the lungs. The small size of the diseased lobes in both these cases seemed to suggest that the affection had dated from childhood.

On one occasion I endeavoured to learn something of the progress of cases of chronic disease of lungs in children which I had seen during life. An attempt was made to trace eight cases some years after they had first come under notice; I was, however, strangely unfortunate. In only three instances my search was successful, the parents having moved where I was unable to trace them. Of the three cases discovered in one, where the heart had been drawn to the right of the sternum, the boy seven years later was in fairly good health, and having left school was engaged in work, I believe, though I have not noted the point, in a boot factory. In another case, where the left side measured 1 inch less in circumference than the right and bronchial breathing was audible over both the upper and the lower lobe, the condition was the same at the end of three years, and the girl, then 12 years of age, proved to be in moderate health. The third case possibly possesses some interest because as early as the age of 13 months fibrosis of the lower lobe of the right lung was apparently present. When the boy was seen four years later, although not perhaps so active in appearance as most boys of his age, he was healthy. looking and had cheeks of good colour. Yet the old physical signs of trouble in the lower lobe of the right lung remained and the heart could be felt pulsating below the right nipple. To these may be added the case already mentioned where disease of the lower lobe of the left lung was thought to have followed the entrance of a sweet into a bronchus. The girl for some time subsequently was an in-patient in a general hospital and was under treatment at intervals there for the space of three years. At the end of four years she was seen and examined by myself. Her appearance was healthy. I could detect no difference in the circumference of the two sides of the chest and the abnormal physical signs were no longer present. The above cases are suggestive, but from so small a number, observed for the space of only a few years, no definite conclusions can be drawn, yet if clinical experience is supplemented by the experience of the postmortem room it possibly will be safe to consider that in children dilatation of the bronchial tubes and fibrosis of the lung do not of necessity materially lessen the prospects of average length of life.

It has been suggested earlier that dilatation of the bronchial tubes when situated in the upper lobe may be mistaken for tuberculous disease. Occasionally, also, tuberculosis of the lung when limited to the lower lobe may lead to difficulty of diagnosis. Tuberculosis of the lungs in children, as is well known, commonly commences in a direct invasion from caseous bronchial glands. This local extension of the disease renders the lower lobe almost as liable to infection as the upper lobe. Limitation of tuberculosis to the lower lobe occurs most commonly in infants, but $I$ have seen the lower lobe alone extensively affected as late as the age of seven years. When the caseous consolidation occupies almost the whole of the lower lobe it may be difficult to differentiate the disease from confluent broncho-pneumonia or pleural effusion may be thought to be present. The mistake of caseous consolidation of the lung for fluid in the pleural cavity is still more likely to occur in those rare instances in which almost the whole of one lung is solid while the opposite lung remains healthy. A case of this kind under the care of a former and now deceased colleague was a remarkable example of the occurrence of simulation of pleural effusion by a caseous lung. A child, aged 17 months, 
had been admitted for what was considered to be empyema of the right side of the chest. A needle was inserted and no pus found, yet so certain was the diagnosis considered to be that the child was operated upon for the removal of the supposed fluid. No fluid, however, could be discovered. The child eventually died and virtually the whole of the right lung was found to be occupied by a caseous mass, while the left lung remained healthy. The caseation was of somewhat unusual character. It shelled out in rounded masses from the interstitial structure of the lung, leaving fibrous strands and remains of bronchial tubes and blood-vessels, with here and there small portions of compressed lung tissue. It may be thought that possibly the disease was not tuberculous, but the presence of caseation in the bronchial and mediastinal glands, of tuberculous ulcers in the small intestine, and of tuberculous dactylitis in one finger seemed to leave no doubt as to its nature.

From time to time one meets with cases in the out-patient room where there is said to have been severe hæmoptysis. History is too often unreliable and the description of the amount of blood coughed up is generally received with some measure of scepticism. In one case, however, a boy, aged four and a half years, brought up about half a pint of blood in the out-patient waitingroom. The cause for the bleeding was not clear. The boy presented nothing which indicated marked ill-health, and there was no evidence of dilatation of the bronchial tubes or of tuberculosis of the lungs. Such instances of severe hæmoptysis may possibly occasionally be due not to tuberculosis of the lung itself but to suppuration in a caseous bronchial lymphatic gland as occurred in the case from which the specimen that Fig. 4 illustrates was taken. In this case, however, suppuration within a caseous gland not only opened a branch of the pulmonary artery but the pus had previously burst into the cesophagus and the blood followed the path formed by the course of the pus. The accident happened in a boy, aged five years, who was at school on Friday, was thought to be unwell on Saturday, and died in the course of a few hours, during which large quantities of blood were brought up, on Sunday. In this case the cause of the bleeding from the lungs was, it is needless to say, perfectly clear, but as an illustration of the obscurity of some cases of hæmoptysis in children the following may be mentioned. A girl, aged seven years, was said to suffer from repeated slight attacks of hæmoptysis, and on one occasion about a teaspoonful of bright blood was brought for examination by the mother as evidence of her statement. Nothing could be found in the lungs or mouth to account for the bleeding. On visiting the home of the child a few years later it was found that she had lived for nearly three years after the time when she was first seen. The bringing up of blood bad continued and had occurred about once every two months. The child's health was said to have remained very good. One day, however, she complained of abdominal pain, vomited several times, and was found dead in bed on the following morning. The cause of the child's death was probably some accident which had no connexion with the hæmoptysis, yet there seems to be a remote possibility that the hæmoptysis may have been the only evidence of disease of the nature of Henoch's purpura in which abdominal symptoms were at first absent. Eventually hæmorrhage may have occurred into the walls of the intestine the shock of which caused death.

Henoch's purpura, it is scarcely necessary to remark, rarely proves fatal in this way. I have, however, made a necropsy on a boy, aged nearly four years, who died as a consequence of hæmorrhage into the walls of the intestines. There had been no passage of blood by the rectum and the nature of his disease was obscure until after death. To discuss, however, questions connected with Henoch's purpura is to wander from chronic affections of the lung in children. Whatever the nature of the hæmoptysis may have been in the above case, the continued good health of the child up to the time of her death seems to be in itself an evidence of the obscurity that may surround the symptom hæmoptysis, which, as in adults, is supposed in children to indicate the presence of sericus disease of the lung.

In conclusion, it may be remarked that while the above observations may appear to be superficial and disconnected they have this in common--that they are intended in some small degree to illustrate the difficulty which may surround the diagnosis of chronic disease of the lung in children and, associated with the difficulty of diagnosis, the need for caution as regards prognosis.

PS.--Since writing the above I have read the valuable paper by Dr. Clive Rivière on Pulmonary Fibrosis in Childhood ${ }^{1}$ which is based upon 40 cases. Dr. Rivière lays stress on the possibility of mistaking the disease for chronic tuberculosis and enters fully into diagnosis and prognosis.

\section{A PROSPECTIVE CURE FOR ELEPHANTIASIS. ${ }^{2}$}

BY W. SAMPSON HANDLEY, M.S., M.D. LOND., F.R.C.S. ENG.,

ASSISTANT SURGEON TO THE MIDDLESEX HOSPITAL AND SURGEON TO THE BOLINGBROKE HOSPITAL; HUNTERIAN PROFESSOR, ROYAL COLLEGE OF SURGEONS OF ENGLAND.

Elephantiasis Arabum has up to the present been regarded as an incurable disease. The improvement which the operation of lymphangioplasty has produced in the following case is so great and striking as to justify the hope that a cure has been found. My experience in other directions has shown that the effect of the operation is not merely transitory.

In this operation a number of stout silk threads running the whole length of the limb are introduced into the subcutaneous tissues of the swollen part. The threads are completely and permanently buried. Their capillary action enables them to replace the trunk lymphatics and to transfer the excess of fluid from the area of lymphatic cdema to regions where the lymphatic circulation is normal, and where consequently the excess of fluid is absorbed and carried off into the general circulation.

In my preliminary communication ${ }^{3}$ on lymphangioplasty $\mathbf{I}$ recorded two cases in which it had been successfully applied to relieve the "brawny arm" of breast cancer. Further experience in this field has confirmed my conclusions and has shown that the effect of the operation in my earliest cases is permanent to date.

The case which I am about to record is the fulfilment of my anticipation that the method could be used with success in elephantiasis. But before this result was reached harsh experience compelled me to recognise that elephantiasis, unlike the lymphatic cedema of breast cancer, cannot be treated on purely mechanical lines. In the latter affection, as I have shown, the lymph of the swollen limb is a sterile fluid, but in elephantiasis there is present a chronic infection of the tissues with micrococci. Vaccination against the infective micrococci, although in itself powerless to reduce the odema, would appear in elephantiasis to be an essential preliminary to the operation of lymphangioplasty. My case is thus at once a vindication and a criticism of the methods associated with the name of Sir Almroth Wright, showing at the same time their power to arrest an infective process and their incapacity to deal with its secondary results.

The patient, a man, aged 46 years, was sent to me in April, 1908, by Dr. J. J. Udale suffering from sporadic elephantiasis of the left leg dating from the year 1895. In that year the left testicle became swollen, hard, and nodular, as if the seat of a sarcomatous growth. The left leg presented patches of erythema and was painful but not at first greatly swollen. The left inguinal glands were enlarged. About 1898 the swelling of the leg became more marked and had since been progressive until the limb had reached its present enormous size. The patient continued up to the present time to have recurrent pyrexial attacks, ushered in by a rigor and headache and accompanied by patchy erythema of the leg: During these attacks the limb was painful, especially at night. He had never been abroad. Since 1895 he had been in various London hospitals. In 1905 he was in the Seamen's Hospital, Greenwich, under the care of Sir Patrick Manson. The leg was incised and portions of tissue were removed, with temporary benefit. The swollen testicle was also incised and its subsequent removal became necessary, owing to an attack of acute sepsis, doubtless of endogenous origin.

1 St. Bartholomew's Hospital Reports, 1905.

2 The case deseribed was shown before the Society of Tropical Medicine on Nov. 20th, 1908 